\title{
As figurações da morte em \\ Vida e morte de M. J. Gonzaga de Sá, de Lima Barreto
}

\author{
The figurations of the death in Vida e morte de M. J. Gonzaga de Sá, \\ by Lima Barreto
}

\author{
José OSMAR DE MELO (D) \\ UEMG, Belo Horizonte, Minas Gerais, Brasil.
}

\begin{abstract}
Resumo: Este ensaio tem por finalidade abordar as figurações da morte em Vida e morte de M. J. Gonzaga de Sá, de Lima Barreto, com vistas a mostrá-las como manifestações da linguagem no plano do enunciado e da enunciação do discurso literário a partir da perspectiva da teoria literária e da filosofia.
\end{abstract}

Palavras-chave: Lima Barreto; Eros; Thanatos; vida; morte; utopia.

Abstract: This article aims to analyze the metaphors of death in the novel Vida e morte de M. J. Gonzaga de Sá, by Lima Barreto, to show them as manifestations of language in the plane of the enunciation and the enunciation of literary discourse from the perspective of literary theory and philosophy.

Keywords: Lima Barreto; Eros; Thanatos; life, death; utopia.

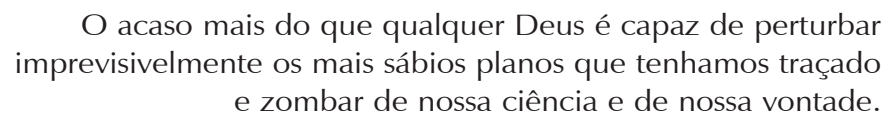

LIMA BARRETO

O tempo é um tecido invisível onde se pode bordar tudo, uma flor, um pássaro, uma dama, um castelo, um túmulo. Também se pode bordar nada. Nada em cima do invisível é a mais sutil obra deste mundo, e acaso do outro. 
A literatura coloca tudo em questão: a linguagem, o homem e as coisas. Por isso, sua função nunca é ilustrar uma verdade - ou mesmo uma interrogação previamente conhecida, mas formular as próprias perguntas.

Quem escreve, escreve junto ao vazio e com o vazio da linguagem. Eis aí uma experiência radical, em que nada está garantido. O escritor, enfeitiçado pelo vazio da linguagem, encontra-se abandonado frente à tarefa de criar, pois "escrever é entrar na afirmação da solidão, onde o fascínio ameaça. É correr o risco da ausência de tempo, onde reina o eterno recomeço" (BLANCHOT, 1987, p.24). Eis aí a escritura como sinônimo de terreno movediço, de ambiguidade, de manifestação da indecidibilidade da linguagem.

A esse respeito, poderíamos, então, indagar: quais são as figurações da morte tornadas possíveis pela literatura? Como escrever a finitude, apresentando, sob forma de texto, a ruína? Qual é a relação entre morte e linguagem? Quais são as vicissitudes que levam à emergência da subjetividade literária na experiência escrita? Em que medida a escrita da morte esvazia mitos e, ao mesmo tempo, constitui uma afirmação e uma libertação para o homem?

É certo que, desde os mitos fundadores da cultura ocidental, a dialética morte e vida vem assumindo, no domínio dos mais variados saberes, feições bastante diferenciadas, mantendo, entretanto, como núcleo comum, a dimensão ambivalente. A literatura, por seu turno, parece ter sabido sempre que a morte e a escrita (linguagem) caminham lado a lado. A escrita seria, então, uma espécie de grande recurso sentimento de que não nos sentimos bem em parte alguma. A escritura seria, pois, a única pátria?

Talvez. Por isso mesmo, a escritura seria uma criatura eutanasiana, já que é nessa espécie de reesvaziamento, perpetrado pela escrita e por sua muito própria relação com os referentes já abolidos, que o extinto encontra seu modo de presença e sua forma de vida. E assim é porque a literatura talvez seja a aventura, o exercício e a astúcia diante da imediatidade perdida, porque se revela na consciência de ser uma criação da escrita (CANÇADO, 2003). É isso: no "inutensílio" da escrita, na espessura engolfante da linguagem, no antipériplo da literatura e da narrativa, a conta da morte não fecha. Dá sempre em outra coisa que não é a morte.

Este é, ao que parece, o caso do romance Vida e morte de $\mathbf{M}$. J. Gonzaga de Sá, de Lima Barreto, que fala de passagem pela morte, de esvaziamento de sentido, de melancolia e de ceticismo, de solidão e de incomunicabilidade. Fala de um eu que não é mais eu, mas um outro, apresentando, então, o vazio como a potencialidade que engendra o saber literário.

Por exemplo, quando lemos o capítulo IX, observamos que grande parte dele e todo o capítulo $X$ são dedicados às exéquias do contínuo Romualdo, grande amigo de Gonzaga de Sá. Nesses dois capítulos nada se fala acerca do biografado. Centra-se no episódio da morte e suas variações, isto é, a relação estreita entre Eros e Thanatos. Imagens de vida e morte se sucedem nesses dois capítulos. Diz o narrador Gonzaga de Sá: "Eu já via o cadáver, na nudez estúpida de coisa e, apesar dela, com uma interrogação a que ninguém até hoje respondeu com segurança - o que vamos ser depois disto"? (BARRETO, 1990, p. 80). 
As imagens que apontam para a oposição vida/morte se sucedem ininterruptamente nesses capítulos e mostram que nesse jogo dialético ora a vida suprassume a morte, ora a morte suprassume a vida. A esse respeito salienta o velho Gonzaga de Sá: "tu bem sabes que é difícil dizer onde começa o real e onde acaba", (BARRETO, 1990, p.91). Assim, a morte converte-se também em fonte de vida, já que nos dá a mais cruel consciência de nossa finitude. Entre as imagens contrapostas do morto que é velado na sala e o grito das crianças que brincam na rua, há a exortação de que a vida e a morte andam imbricadas.

Freud, pensando a questão, colocava a morte na origem do próprio pensamento, considerando-a "o ponto de partida de toda especulação" (FREUD, 1974, p. 14). Acerca da morte, Gonzaga de Sá afirma: "A morte tem sido útil e será sempre. Não é só a sabedoria que é uma meditação sobre ela - toda a civilização resultou da morte" (BARRETO, 1990, p. 27). Daí a correlação entre morte e utopia. No fundo, o desejo da utopia talvez seja o desejo do retorno ao lugar de origem, da indiferenciação (desejo do não-lugar?) e da ausência de desejo.

Durante o féretro, as plumas dos chapéus femininos nas janelas contrastam com o clima de tristeza dos que passam acompanhando o enterro. Poderíamos citar ainda uma série de outros contrastes que opõem Eros e Thanatos na narrativa, tais como luta versus capitulação, sociedade versus indivíduo, insulamento versus comunicação, solidão versus convivência, utopia versus ideal, real versus ficção etc.

A antítese vida/morte ecoa também na hesitação entre o ato de pensar (vida) e a ausência de pensamento (morte). $\mathrm{Na}$ perspectiva de Augusto Machado e de Gonzaga de Sá, o pensamento é o responsável pelo estado de insulamento que ambos sofrem em relação aos demais. A propósito da questão, Augusto Machado reflete:

(...) Longe de me confortar, a educação que recebi só me exacerba, só fabrica desejos que me fazem desgraçado, dando-me ódios e, talvez despeitos! Por que ma deram? Para eu ficar na vida sem amor, sem parentes e, porventura, sem amigos? Ah! Se eu pudesse apagála do cérebro! Varreria uma por uma as noções, as teorias, as sentenças, as leis que me fizeram absorver; e ficaria sem a tentação danada da analogia, sem o veneno da análise. (...) (BARRETO, 1990, p. 81-82)

Augusto Machado, ao se posicionar de modo tão pessimista em relação à sua instrução, expõe a triste realidade do mulato em uma sociedade recém-saída da escravidão. É a consciência de que, mesmo instruído, não teria espaço nela. A revolta do mulato reflete sua condição de excluído. Daí, o desejo da alienação para não se perceber como sujeito do entrelugar. Na fala do narrador, surge, ao que parece, a voz áspera e amarga de Lima Barreto, assinalando que, em uma sociedade moldada para o branco e pelo branco, não havia lugar para o negro, a menos que ele se destruísse enquanto tal.

Na concepção de Gonzaga de Sá, a morte tem sido útil para, ao se meditar sobre ela, compreender melhor a ausência de vida no cotidiano. No trajeto do carro fúnebre, sob um sol escaldante, pensa com estrelas, nuvens e ventos que o processo de racionalização do mundo o transformou em um espaço de desencanto. A sua melancólica saudade instiga o movimento para as pressuposições teóricas organizadas 
em linha geométrica e as periodizações abruptas, que petrificam a utopia de uma reconciliação. Por isso, por ocasião do transporte do féretro, surgem as marcas da luminosidade, como metáfora da celebração da morte. É preciso saber que existe a morte para que se possa viver. Diz Gonzaga de Sá:

- Como está lindo o dia! Até alegre, não achas? Nem parece que levamos um morto... É que ele não goza da vida. Antes assim!... Morrendo, em nada perturbou a vida das coisas e dos outros; entretanto, dizem, a sociedade é uma associação simpática de indivíduos e pouca coisa separa o homem do mundo (BARRETO, 1990, p. 95).

O narrador compartilha com Gonzaga de Sá de uma curiosidade cotidiana em relação àquilo que o toca, com um dinamismo e humanidade no olhar, capaz de associar paisagens e sentimentos díspares. E é esse olhar humanizado que escava a superfície e pinta um perfil humano, retirado do anônimo movimento das ruas: os "pais de família":

Graves homens de fisionomia triste, curvados ao peso da vida, sobraçando alongados embrulhos de pão, caminhavam ao nosso lado com o passo tardo, e econômico, poupado, de velhos bois de carro. A estrada da vida era má; areenta, aqui; encharcada, ali; e mais além, íngreme e empedrouçada... Só a paciência deles, só aquela rija musculatura que se gastava às gotas, só ela poderia levar avante o carro da mulher e dos filhos. Com o jornal debaixo do braço, iam ruminando grandes combinações de tostões (BARRETO, 1990, p.83).

Com essa pintura da vida urbana, realiza-se a síntese do movimento do olhar do narrador: da natureza à paisagem urbana, desta à natureza - escavando a superfície em busca da profundidade. Tudo a partir de um único eixo - o homem, porque costura o interior à superfície, a forma aparente ao conteúdo, com a sutileza dos fios da memória.

Por isso, justapõe à imagem urbana outra pintura de idílica abordagem da vida no campo, da qual se abstrai o trabalho, o sofrimento, a fome, para introjetar tolerância, paciência: o clássico cenário das vidas no campo, que pagam tributo ao poder. Diz o narrador personagem:

Na minha meninice, nos arredores do Rio, eu tinha visto espetáculo que agora a imaginação associava a este. Era por aquela hora dourada da tarde, mais cedo um pouco, mas já as montanhas se tinham adelgaçado para sofrer a carícia imaterial de um céu rarefeito. Uma longa fila de carros de bois, cheios de verduras, carvão e lenha, desfilava pela estrada. Os carreiros gritavam de quando em quando; os bois mastigavam o passo; por vezes, alongavam a língua, um inclinando-se sobre outro, a fim, talvez, de melhor dividir o esforço de tracção... Oh! A solidariedade da carga (BARRETO, 1990, p. 83-84).

O olhar de Augusto Machado para a paisagem, e os homens, enxerga-os numa trágica justaposição - em meio à estrada cujas "bordas salpicadas de frutas vermelhas", envolvida "na poeira que o sol, no poente, avermelhava e dava faiscações de ouro" - em meio à vida, no espaço habitual da vida cotidiana, os homens estavam abraçados à morte. Essa, compreendida no sentido de vida vazia de sentido, alienada. Assim, a submissão e infelicidade imprimem suas marcas no corpo dos homens que, sob o aguilhão, não podem caminhar eretos. "Viviam 
sob o aguilhão dos deveres e com a vaga esperança consoladora da afeição eterna dos filhos" (BARRETO, 1990, p. 84). O fardo da rede de deveres afasta "os pais de família" da vida, humana e essencial em seus valores, deixa-os curvados, submissos, portanto, mortos.

Com o olhar sumamente concentrado em imagens da própria vida, sem a curiosidade investigadora nem tampouco com ânimo para olhar para trás (quando rememoram também estão presos a uma realidade fechada, explicada por dogmas, preconceitos e pela doxa, para lembrar Sócrates), esses homens têm sua identidade humana abafada, sob o "peso da vida". A respeito deles, Augusto Machado afirma: "Nem sabiam, aqueles animais, de sua força; nem suspeitavam que toda uma cidade esperava aquelas úteis ou saborosas coisas que só a sua paciência e a sua força poderiam arrastar por sobre aqueles caminhos instáveis" (BARRETO, 1990, p. 85).

Sem qualquer perspectiva maniqueísta, o narrador amplia o olhar e desvenda o conteúdo complexo das relações sociais: nelas residem as forças mistificadoras que a repetição, a alienação e o automatismo transformam em essência de vida.

Podemos, aliás, observar o desafio fundamental da existência - jogo entre a vida e a morte - no grau de imprevisibilidade da narrativa, que caminha por meio de associações soltas e descontínuas, comandadas pelo Acaso, destruidor implacável de esperanças. Acerca disso, salienta o narrador: “(...) o Acaso, mais do que qualquer Deus, é capaz de perturbar imprevistamente os mais sábios planos que tenhamos traçado e zombar de nossa ciência e de nossa vontade. E o acaso não tem predileções" (BARRETO, 1990, p. 26).
Sobre o dilema existencial, o narrador afirma peremptório: “(...) - por que razão se vive?" e, ironicamente, diz: “(...) - Eu julgo (...) que os desgraçados se deviam matar em massa a um só tempo. Schopenhauer, que propôs o suicídio da humanidade, foi longe; devem ser só os desgraçados, os felizes que fiquem com a sua felicidade (...)". A morte tem também um motivo de sonho para Gonzaga de Sá, porque dá liberdade em relação ao real. Isso pode ser verificado quando o devaneio transforma as visões merencórias e fúnebres de Gonzaga de Sá: “(...) sonho também por minha conta, ao jeito dos meus mortos; e os meus sonhos são mais belos porque são imponderáveis e fugazes (...)" (BARRETO, 1990, p. 22).

A marca evidente desse processo, já anunciado no título do romance - Vida e morte de M. J. Gonzaga de Sá -, dá-se na configuração da morte como linguagem ou quando protagonista e narrador são projetados no velório e enterro de um amigo. Não se espere, no entanto, uma descrição realista de cenas de morte. Ao contrário, a morte, vista como um dos aspectos do círculo da vida, permite que, em seu ambiente, transpire excitação, desejo, êxtase e beleza, pois ela é, no plano da escritura, apenas, jogo de linguagem e poiesis.

Tal é a tentativa de vencer a morte que o narrador a erotiza. Assim, no torpor de um velório o encontro de Augusto Machado com uma jovem mulher tornaraos, como num baile, inebriados um do outro, deslocando o estático sentido de morte para revertê-lo em sensualidade envolvente, logo na afirmação de Eros, que é o instinto de vida. Ao ver a moça Alcmena, o narrador Augusto Machado, extasiado com sua beleza, diz: 
Pousei o meu olhar nos seus olhos revirados, e segui deles até uma estrela que brilhava muito próxima das nossas cabeças. Nessa rápida postura, a moça atraía fortemente. Seus seios pareciam intumescidos, o pescoço longo e roliço, saía todo do corpete, e as formas miúdas desenhavam-se com relevo por entre as dobras do vestido.

(...) Ainda lhe vi a tez macia, os cabelos castanhos, as mãos longas e bonitas, um pouco estragadas pelo trabalho doméstico... Depois, nasceram-me coisas obscenas; vagos e indefinidos desejos cresceram em tumulto, de roldão; borbulhavam, subiam e desciam dentro de mim, encontravam-se, faziam-se outros a exigir satisfação, carícias, estados enervados e deliciosos... (BARRETO, 1990, p. 88-89).

A morte como imagem da descontinuidade desperta em Augusto Machado o desejo de vida, de permanência, de continuidade. Ou seja, "o erotismo", como salienta Bataille (1980, p.13), "é a aprovação da vida até na própria morte". Assim, a situação extrema da morte é associada ao sexo, fonte originária de vida, que tenta a todo custo se refazer, ainda que em forma utópica. Seu efeito, por isso mesmo, não é apenas destrutivo, mas reconstrutor.

Daí o desejo sexual do narrador por Alcmena e o arrebatamento de sentimentos obscenos que Ihe tumultuam a alma. A continuidade, dinâmica e complexa, anula a disparidade entre os extremos vida/morte, torna-os equivalentes, pressupondo-se, mútua e necessariamente, num anseio de totalidade só possível através da arte. Assim, a imagem do cadáver suscita revelações de vida, enquanto esta muitas vezes por sua solidão e anonimidade representa uma morte ao modo moderno. Assim, encontramos na conotação positiva dada à morte, sinais de resistência utópica, a qualquer custo, quando o narrador diz:

Demais, senti também, era o cadáver que me impelia, que me empurrava para a moça; (...) Vivente, tinha vivido, pois tanto é forte em nós viver, que só em nós mesmos encontramos a razão e o fim da vida, sabendo todos nós que devemos continuá-la a todo o transe, custe o que custar, em nós mesmos e nos nossos descendentes (BARRETO, 1990, p. 90).

A imagem da morte também permite uma melhor percepção do coletivo, agitado, inquieto frenesi das pessoas nas ruas que, nos seus dias normais, mantém a indiferença brutal e o isolamento insensível de cada indivíduo em seus interesses privados; porém, no percurso de Augusto Machado em direção ao velório, o tumulto das ruas deixa de ser menos agressivo à natureza humana: a sensação de ir ver um morto imprime conteúdo de humanidade ao olhar que sente a multidão. Diz, então, o narrador: "O veículo ia cheio. Viajei comprimido com volúpia, sofrendo aquele contato humano; dando-me bem ao absorver a maior porção do calor vital do meu semelhante próximo. Não estava só no mundo e toda aquela gente tinha que morrer, como eu" (BARRETO, 1990, p. 80).

Assim, a caminho de velar um morto, Augusto Machado faz um percurso contrário à morte e, mesmo nos sufocantes encontros em multidão, pode transpirar, sutilmente, solidariedade, em passageira identificação com os outros.

Tudo, nos capítulos IX e X, do Gonzaga de Sá aponta para a irregularidade, para a multiplicidade e para a precariedade: objetos, ruas, casas, alguns personagens, a existência humana, o tempo: as épocas se misturam; os anos não são marcados pelas 
coisas mais duradouras e perceptíveis. No plano da narrativa, por exemplo, esse movimento pendular se caracteriza na misteriosa e "mal" esboçada personagem Alcmena, que surge como que por milagre no enredo, travando uma conversa recheada de erotismo e sensualidade com o personagem-narrador, no momento em que este velava Romualdo, o compadre de Gonzaga de Sá. Logo em seguida, ela desaparece sem mais nem menos, como se fosse uma figurante que, cumprido seu papel, já não é mais necessária ao roteiro do romance.

Essas oscilações no Gonzaga de Sá parecem caracterizar o que se poderia chamar de crise da linguagem. A presença da descontinuidade está presente em todos os planos do romance, cuja estrutura dialética integra elementos díspares ou antípodas, como vida/morte, real/ imaginário, ser/parecer, homem/natureza, ficção/real, subjetividade/objetividade, ao incluir no ilusório continuum de todas as coisas o elemento imprevisível. Daí, o desabafo de Gonzaga de Sá: - "Essa (des)continuidade é imposta por tudo. As folhas que caem adubam as raízes das árvores onde nasceram, para fazerem nascer outras novas e belas" (BARRETO, 1990, p. 89).

Nesse sentido, o protagonista parece conceber a morte não como ameaça, ruptura, descontinuidade, mas como eterna renovação de todas as coisas. Assim, poderíamos dizer que, na concepção do protagonista, continuidade e descontinuidade são faces de uma mesma moeda.

É no plano social, no entanto, que Gonzaga de Sá extrai da reflexão sobre a morte as maiores consequências. A lição é em primeiro lugar manifesta pelo jovem amigo, que diz: "Não há civilização isenta de crimes e erros" (BARRETO, 1990, p. 96). Gonzaga de Sá dará forma melhor acabada à ideia: “- E a morte tem sido útil, e será sempre (...) (BARRETO, 1990, p. 96).

A propósito, o protagonista, mediante uma lição de sabedoria, ensina seu discípulo a ter consciência da morte em todos os planos de sua manifestação ao chamálo à cerimônia fúnebre: "Deves ir não só porque é conveniente à tua mocidade o espetáculo da morte, como também dá campo para se ver como os etnólogos são falsos e maus" (BARRETO, 1990, p.97).

No próprio Gonzaga de Sá, a morte do compadre terá profunda repercussão. Torna-o mais pessimista. Leva-o de um extremo ao outro. Enfim, a um estado de descentramento que o faz ainda mais enigmático, como se de fato as regiões interiores da morte em que mergulha fossem indevassáveis. Em breve, deixará a cena do mundo, mas desde então se sente com o seu amigo do outro lado da vida, em espaço utópico, ao afirmar o seguinte:

Do outro lado, pela alameda que corria defronte do botequim víamos agitar-se, ao impulso de energias acumuladas durante a semana, uma multidão policrômica; e ali, separados dela, silenciosos e inertes às forças que a moviam, nós estávamos como fora da humanidade como antes de outra estrutura, sem nada em comum com ela. $O$ grande relvado circular que dividia as duas alamedas, com seu repuxo ao centro, marcava o limite entre os dois meios fluidos, próprios à vida deles e à nossa. Víamo-los como o passageiro vê os peixes, da borda do navio, através das águas prateadas (BARRETO, 1990, p. 100).

Acompanhando o percurso da luz, surge a metáfora da utopia - as palmeiras árvore contígua à casa de Gonzaga de Sá. 
Aqui, elas contrastam com o plano baixo da morte. Diz o personagem-narrador: "O sol continuava claro e as alturas eram mais límpidas. O perfil das palmeiras resultava mais firme e os ciprestes não despertavam ao forte sol do dia" (BARRETO, 1990, p. 97).

No dia do enterro, o narrador, fascinado pela luminosidade do dia, ao contemplar o mar, parte em direção a uma viagem imaginária em busca de um espaço edênico. E o que lhe chama a atenção, no mar, é a indiferença da natureza no que tange às vicissitudes existenciais, como a morte, a dor e a solidão. Gonzaga de Sá estava indo velar o amigo, mas a natureza, em seu devir inexorável, seguia, indiferente, seu curso, "à mercê dos caprichosos movimentos do abismo":

E me pus a pensar que sobre a convexidade livre do planeta que me fez, não tinha um lugar, um canto, uma ilha, onde pudesse viver plenamente, livremente. Olhei o mar de novo. Boiavam sargaços, balouçando-se nas ondas, indo de um para outro lado, indiferentes, à mercê dos movimentos caprichosos do abismo. Felizes! (BARRETO, 1990, p. 99).

A visão utópica se torna explícita e direta no capítulo seguinte:

Quis ali, em segundos, organizar minha República, erguer a minha Utopia e, por instantes, vi resplandecer sobre a terra dias de Bem, de Satisfação e de Contentamento. Vi todas as faces humanas sem angústias, felizes, num baile! Tão depressa me veio tal sonho, tão depressa ele se desfez. Não sei que lógica diabólica me dominava. (BARRETO, 1990, p. 108).

O que fica claro é que o traço utópico está presente desde o início, quando
Gonzaga de Sá manifesta ao amigo o gosto por balões, coerente com a vontade de voar, expressa desde a infância e realizada na tentativa do inventor, narrada no capítulo de abertura. Ele pretendia atingir o espaço da utopia. Diz ele: "Iria subir, iria remontar os ares, transmontar cordilheiras, alçar-se longe do solo, viver algum tempo quase fora da fatalidade da terra, inebriarse de azul e de sonhos celestes, nas alturas rarefeitas" (BARRETO, 1990, p. 26).

No entanto, essa região talvez só possa ser atingida pela Morte, cuja mão age sob a lei do Acaso, que destruiu a aeronave do construtor, misto de poeta e cientista. Ao final do livro, quando retoma a questão da possibilidade utópica, na criação do afilhado, deixado órfão pelo compadre de Gonzaga de Sá, ainda pequeno, sabe-se que a mágoa de viver pode ser maior que a morte, mas ainda assim a frase final do romance não sugere a fuga à luta: "A felicidade final dos homens e o seu mútuo entendimento têm exigido até aqui maiores sacrifícios..." (BARRETO, 1990, p. 131).

Ao que parece, se só a proximidade da morte lhe deu, assim, forte e nítido, o prazer de viver, o biógrafo de Gonzaga não era pessimista: entre os homens se achava isolado e hostilizado, mas a natureza o acolhia com jeito maternal e, através dela, sentia-se radicado à vida. Ao contemplar, por exemplo, do Passeio Público, o sol se pôr, envolveu-o uma apaziguadora sensação de solidariedade com tudo o que existia. Diz o narrador personagem:

Saturei-me daquela melancolia tangível que é o sentimento primordial da minha cidade. Vivo nela e ela vive em mim! (...) Por isso, já me apóio nas coisas que me cercam, familiarmente, e a paisagem que me rodeia não me é inédita: conta-me a história comum 
da cidade e a longa elegia das dores que ela presenciou nos segmentos de vida que precederam e deram origem à minha (BARRETO, 1990, p. 21-22).

Na verdade, o Gonzaga de Sá já reflete àquela época o drama do homem moderno no grande centro urbano, no qual ele tem com a morte, quer queira, quer não, convivência absolutamente inevitável. Aliás, mesmo quando surge envolta no véu da arte, sua presença não deixa de ser menos temível, já que a convivência com ela no ato da criação parece atrair para mais perto o fim. Aliás, seu espectro espanta sob qualquer aspecto.

Daí o fato de o Gonzaga de Sá oscilar nesse embate entre Eros e Thanatos. Um tende à celebração da vida; o outro tende a reconduzir o homem em direção à indiferenciação e a uma inorganização originais, como diz Norman Brown (BROWN, 1974, p.87). Essas forças antinômicas despertam no homem $\mathrm{O}$ desejo de reconquista do paraíso perdido. Talvez seja dessa busca que nasça a ilusão da utopia.

De algum modo, Gonzaga de Sá busca a utopia. Tenta-a na construção da aeronave, no entanto, ela não voa. Procura-a na solidão, mas descobre ao fim da vida o malogro de sua ilusão, ao descobrir que "Vênus é uma deusa vingativa". Apenas num único momento, ao longo da narrativa, o protagonista lamenta o fato de não ter amado nem de ter tido filhos. Enfim, não havia, como Brás Cubas, transmitido a nenhuma criatura o legado de sua (e também nossa) miséria.

No entanto, não se desespera com isso, já que faz o elogio da morte. Aliás, em momento algum Gonzaga de Sá mostrou temer a morte. Pelo contrário, essa indesejada das gentes o fascina e ele, ao longo de sua existência, não lamenta sua morte em efígie. Na verdade, a morte, na perspectiva de Gonzaga de Sá, manifestase, ao que parece, como uma metafísica da esperança e não do desespero.

Daí, em vez de dualismo, temos, na narrativa, a dialética, já que Eros e Thanatos, em Vida e morte de M. J. Gonzaga de Sá, de Lima Barreto, despistam nos meandros do dizível e do indizível, ou seja, do disfarce e da ambiguidade da linguagem, a nossa verdadeira condição: a de seres transitórios, errantes, sem roteiros definidos e, ademais, assinalados por uma maldição irremediável: a finitude.

\section{Referências}

BARRETO, Afonso Henriques de Lima. Vida e morte de M. J. Gonzaga de Sá. Rio de Janeiro: Garnier, 1990.

BARRETO, Afonso Henriques de Lima.

Cemitério dos vivos. São Paulo: Brasiliense, 1961.

BARRETO, Afonso Henriques de Lima. Diário Íntimo: Memórias. São Paulo: Brasiliense, 1961. (Prefácio de Gilberto Freyre).

BATAILLE, George. O erotismo: o proibido e a transgressão. 2. ed. Trad. João Bernard da Costa. Lisboa: Moraes Editores, 1980.

BLANCHOT, Maurice. L'écriture du désastre. Paris: Gallimard, 1980.

BLANCHOT, Maurice. "A obra e o espaço da morte." In: BLANCHOT, Maurice. O espaço literário. Rio de Janeiro: Rocco, 1987. p. 81-159.

BROWN, Norman. Vida contra morte. Petrópolis: Vozes, 1974.

CANÇADO, José Maria. Memórias videntes do Brasil: a obra de Pedro Nava. Belo Horizonte: Ed. UFMG, 2003.

DERRIDA, Jacques. A escritura e a diferença. São Paulo: Perspectiva, 1967. 
FREUD, Sigmund. O humor. Trad. Jayme

Salomão. In: FREUD, Sigmund. $\mathbf{O}$ futuro de

uma ilusão. Rio de Janeiro: Imago, 1980. V. 21. p. 189-194.

SCHWARCZ, Lilian Moritz. Lima Barreto: triste visionário. São Paulo: Companhia das Letras, 2017.

Recebido em: 21/01/2019

Aceito em: 13/03/2019

Publicado em: 00/05/2019

\section{Autor:}

José OSMAR DE MELO

Possui graduação em Filosofia pela Pontifícia Universidade Católica de Minas Gerais - PUC Minas, Belo Horizonte, (1987); graduação em Letras: Língua Francesa pela Universidade Federal de Minas Gerais - UFMG, Belo Horizonte, (1994); graduação em Letras: Língua Portuguesa pela Universidade Federal de Minas Gerais - UFMG, Belo Horizonte, (1992); Mestrado em Literaturas de Língua Portuguesa (subárea: Literatura Brasileira) pela Pontifícia Universidade Católica de

Minas Gerais - PUC Minas, Belo Horizonte, (1997), Doutorado em Literaturas de Língua Portuguesa (subárea: Literatura Brasileira) pela Pontifícia Universidade Católica de Minas Gerais - PUC Minas, Belo Horizonte, (2004) e Pós-Doutorado em Literatura Brasileira pela Universidade do Estado do Rio de Janeiro - UERJ, Rio de Janeiro (2014). Atualmente, é professor de Língua Portuguesa, Filosofia e Introdução à Metodologia Científica da Universidade do Estado de Minas Gerais - UEMG e pesquisador do grupo de pesquisa Estudos de Literatura e Cultura da Belle Époque - LABELLE, sob a coordenação da pesquisadora Carmem Lúcia Negreiros de Figueiredo, no Instituto de Letras da Universidade do Estado do Rio de Janeiro - UERJ.

Orcid: http://orcid.org/0000-0002-9792-866X

E-mail: joseosmarmelo@hotmail.com 